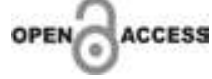

RESUMO DE ARTIGO

\title{
Impacto da Osteonecrose da Cabeça Femoral na Qualidade de Vida de Crianças e Adolescentes
}

\author{
Necrosis of the Femoral Head and Health-Related Quality of \\ Life of Children and Adolescents
}

\author{
Marcos Almeida Matos ${ }^{1}$, Luanne Liesle dos Santos Silva ${ }^{1}$ \\ ${ }^{1}$ Serviço de Ortopedia e Traumatologia do Hospital Santa Izabel; \\ Salvador, Bahia, Brasil
}

\begin{abstract}
Correspondence addresses: Dr. Marcos Almeida Matos marcos.almeida@hotmail.com
\end{abstract}

Received: April 13, 2019

Revised: May 31, 2019

Accepted: June 4, 2019

Published: June 28, 2019

Data Availability Statement: All relevant data are within the paper and its Supporting Information files.

Funding: This work was the result of authors' initiative. There was no support of research or publication funds.

Competing interests: The authors have declared that no competing interests exist.

Copyright

(C) 2019 by Santa Casa de Misericórdia da Bahia. All rights reserved.

ISSN: 2526-5563
Objetivo: Verificar o impacto da necrose avascular da cabeça do fêmur sobre a qualidade de vida de crianças e adolescentes com doença de Perthes e anemia falciforme. Material e Métodos: Estudo comparativo com 24 crianças entre oito e 18 anos com necrose avascular da cabeça do fêmur secundária à doença de Perthes e à anemia falciforme (grupo com necrose) e 24 crianças consideradas assintomáticas (grupo sem necrose). Foram coletados dados clínicos e sociodemográficos e aplicado o instrumento PedsQL 4.0 e o escore de Charnley para disfunção do quadril. Resultados: Não houve diferença no escore global e em nenhum domínio comparando os grupos Perthes (global=73,1) e anemia falciforme (global $=65,9$ ). Quando comparados os grupos sem necrose e com necrose, nota-se que o grupo Perthes tem escore inferior apenas para o domínio Capacidade Física $(87,5$ versus 68,5); já o grupo anemia falciforme tem escore global inferior $(64,9$ versus 79,4$)$ e também nos domínios Capacidade Física $(68,5$ versus 87,5) e Aspecto Escolar (62,9 versus 73,7). Conclusão: A necrose avascular da cabeça do fêmur produz escores de qualidade de vida inferiores tanto na avaliação global, como nos domínios Capacidade Física e Aspecto Escolar. Foram identificadas presença de necrose, lesão bilateral e função do quadril como fatores associados à perda de qualidade de vida. Nível de evidência III, Estudo seccional comparativo.

Palavras-chave: Necrose da Cabeça do Fêmur; Hip; Quality of Life.

Objective: To verify the impact of avascular necrosis of the femoral head on the quality of life of children and adolescents with Perthes disease and sickle cell disease. Material abd Methods: A comparative study including 24 children between eight and 18 years old with avascular necrosis of the femoral head secondary to Perthes disease and sickle cell disease (Group with Necrosis) and 24 children considered asymptomatic (Group without Necrosis). Clinical and sociodemographic data were collected and the PedsQL 4.0 and the Charnley score for hip dysfunction were applied. Results: There was no difference in the overall score and in any domain when comparing the Perthes group (global $=73.1$ ) and the sickle cell disease group $($ global $=65.9)$. When comparing the groups with necrosis and without necrosis, the Perthes group had a lower overall score only for the Physical Functioning domain (87.5 versus 68.5 ); sickle cell disease group had a lower overall score (64.9 versus 79.4) and in the Physical Functioning (68.5 versus 87.5) and School Functioning Resumo do artigo: Matos MA, Silva LLDS, Alves GB, de Alcântara WS Júnior, Veiga D. Necrosis of the Femoral Head and Health-Related Quality of Life of Children and Adolescents. Acta Ortop Bras. 2018;26(4):227-230. 
(62.9 versus 73.7) domains. Conclusion: Avascular necrosis of the femoral head produces lower quality of life scores both in the global evaluation and in the domains Physical Functioning and School Functioning. Necrosis, bilateral lesion, and hip function were found to be associated with the loss of quality of life. Level of Evidence III, Sectional comparative study.

Keywords: Femur Head Necrosis; Hip; Quality of Life.

\section{Introdução}

A necrose asséptica da cabeça femoral é uma desordem rara, porém pode acometer crianças e adolescentes susceptíveis. As principais doenças que podem levar à osteonecrose são a anemia falciforme, doença de Perthes (necrose considerada idiopática), displasia do quadril (luxação congênita do quadril), uso de corticoides (doenças reumáticas), cirurgias no quadril e o deslizamento da epífise da cabeça femoral.

A necrose avascular ocorre por interrupção do fluxo sanguíneo para a cabeça femoral, o que ocasiona infarto ósseo de variável intensidade e extensão. Após o insulto, a cabeça femoral tornase vulnerável ao colapso e deformação, antes de iniciar sua remodelação. As consequências desta destruição óssea levam a dor, limitação funcional e destruição parcial ou total da cabeça femoral. Esta sequência de eventos tem reflexos danosos à saúde e funcionalidade não só do quadril acometido, mas principalmente sobre as atividades sociais e de vida diária dos indivíduos.

Muito se discute sobre etiologia, clínica e tratamento da necrose da cabeça femoral, mas pouco ainda se sabe sobre suas consequências negativas na vida das pessoas. Especialmente na criança e no adolescente, o impacto desta desordem pode ser devastador sobre sua qualidade de vida. Por este motivo, avaliamos a qualidade de vida relacionada à saúde de duas das mais importantes causas de osteonecrose da cabeça femoral nesta faixa etária: a doença de Perthes e a anemia falciforme.

\section{Material e Métodos}

Foi realizado estudo de corte transversal comparativo, incluindo três grupos de indivíduos na faixa etária infantil (até 21 anos). O primeiro foi o grupo Controle, com crianças saudáveis; o segundo foi o grupo Perthes; e o terceiro foi o grupo Anemia Falciforme.

A necrose da cabeça femoral foi diagnosticada por meio de radiografias simples da bacia, seguindo a classificação de Severin e Cattterall para esqueleto imaturo. A avaliação funcional do quadril foi realizada de acordo com o escore de Charnley modificado. Para avaliação da qualidade de vida foi utilizada a versão brasileira do questionário psicométrico PEDSQL 4.0.

Para efeito de análise, os grupos com e sem necrose foram comparados entre si e também os três grupos - Controle, Perthes e Anemia Falciforme - tiveram sua qualidade de vida relacionada à saúde comparada em busca de diferenças significantes.

\section{Resultados}

O grupo com necrose avascular teve escore de qualidade de vida global menor que o grupo Controle $(79,9$ versus 69,4). As principais diferenças foram encontradas no domínio da função física $(87,5$ versus 66,8$)$ e no domínio social $(73,7$ versus 62,9). Quando os três grupos foram comparados entre si, crianças e adolescentes com anemia falciforme obtiveram piores escores de qualidade de vida global $(65,9)$, nos domínios físicos $(65,1)$ e atividade escolar $(53,7)$.

\section{Discussão e Conclusão}

Anecrose avascular da cabeça femoral impacta negativamente na qualidade de vida relacionada à saúde de crianças e adolescentes, produzindo escores globais menores e também menor pontuação nos domínios físico, social e escolar. 
O grupo com piores escores correspondeu aos indivíduos portadores de anemia falciforme.

A deterioração da articulação do quadril com sua consequente perda funcional e dor é capaz de prejudicar de maneira importante e irreversível a qualidade de vida relacionada à saúde das crianças. A maioria dos casos de necrose ocorre em pessoas já acometidas por outras doenças que, normalmente, são crônicas e degenerativas. A sobreposição de uma comorbidade como a necrose, pode causar ainda mais sofrimento humano e interferência com as atividades dos indivíduos.
$\mathrm{Na}$ anemia falciforme, o estigma e a relação com vulnerabilidade social é muito grande, fazendo com que a necrose tenha maior impacto, acrescentando maiores perdas na funcionalidade e qualidade de vida de pessoas já com graves problemas na condução de sua vidas diárias, na atividades sociais e escolares.

Concluímos que o tratamento precoce para minimizar o efeito da necrose da cabeça femoral, associado a adequado suporte social deve ser o caminho para amenizar o sofrimento humano e restituir um pouco da qualidade de vida destas crianças e adolescentes. 